\title{
BITING BEHAVIOR OF ANOPHELES MOSQUITOES IN COSTA MARQUES, RONDONIA, BRAZIL
}

\author{
Terry A. Klein, Jose B.P. Lima and Amazonia Toda Tang
}

\begin{abstract}
Mosquito collections were made in and near Costa Marques, Rondonia, Brazil, to determine anopheline anthropophilic/zoophilic behavior. Collections from a non-illuminated, bovine-baited trap and indoor and outdoor human-bait collections were compared. Anopheles darlingi and Anopheles deaneorum were more anthropophilic than the other anophelines collected. The remainder of the Anopheles species were collected much more frequently in bovine-baited traps than in human-bait collections. Anopheles darlingi and An. deaneorum were more frequently collected inside houses than the other anopheline species. But, when collections were made in a house with numerous openings in the walls, there were few differences in the percentages of each species biting man indoors versus outdoors. Anopheles darlingi was the predominant mosquito collected, both inside and outside houses, and had the strongest anthropophilic feeding behavior of the anophelines present.
\end{abstract}

Key-words: Anopheles sp. Brazil, Behavior, Anthropophilic. Zoophilic.

The incidence of malaria in the Amazon Basin of Brazil has steadily increased over the last ten years?. Marques ${ }^{10}$ outlined many of the problems associated with malaria control and environmental and social factors in Brazil which influenced the increasing malaria trends through 1989. But, in addition, vector behavior and feeding preference also affect the intensity of malaria by governing the human-vector contact 12 .

Feeding preferences and host behavior have an important influence on the local epidemiology of malaria. For example, malaria prevalence may be less in communities where the principal malaria vector is not strictly anthropophilic and where cattle range between the villages and major breeding sites ${ }^{8}$. In some areas of Brazil, observations indicate that local populations of mosquito species are zoophilic, while in others they are anthropophilic ${ }^{2}$. It is now apparent that these differences are often species differences within species complexes 2 .

Departments of the 1 rmy and Defense of the United States. Instituto de Biologia do Exército, Rio de Janeiro, RJ, Brasil. Laboratório Central de Entomologia, Divisão de Malária, SUCAM/MS, Brasilia, DF, Brasil.

This study was supported by the US Army Medical Research and Development Command, Grant DAMD17-84-6-4004 to the University of Brasilia, DF, Brazil.

Núcleo de Medicina Tropical e Nutriçāo, Universidade de Brasília, Brasilia, DF, Brasil.

Address to: Major Terry A. Klein. Division of CD\&I. Walter

Reed Army Institute of Research, Washington, DC 20307-5100.

Recebido para publicação em 31/01/91.
In our studies, the host attraction of anophelines to bovines and man were compared to identify differences in species behavior. Residences in the small frontier town (house 1) and in a rural area (house 5) 7 $\mathrm{km}$ from Costa Marques were sampled to evaluate the malaria vector potential in different environments?

\section{MATERIAL AND METHODS}

Mosquitoes were collected on human-bait (inside and outside houses) and in a non-illuminated bovinebaited trap (Figure 1) near house 1 in the town of Costa Marques ( $\left.12^{\circ} 26^{\prime} \mathrm{S}, 64^{\circ} 14^{\prime} \mathrm{W}\right)$, Rondonia and near a corral at house $5,7 \mathrm{~km}$ from town along road BR 429 leading to Presidente Medici. Detailed descriptions of the areas and houses were provided by Klein and Lima ${ }^{7}$. House 1 was made of wood construction with open eaves and unscreened windows and doors. House 5 was poorly constructed having numerous gaps $>2.5$ $\mathrm{cm}$ between the wall boards. Collections were conducted alternately at house 1 (urban) and then house 5 (rural) for each collection period from April 1987 through September 1987. One volunteer conducted human-bait collections for 40 minutes at the beginning of each hour from 1800 to $0700 \mathrm{~h}$ by exposing their feet and lower legs to natural populations of mosquitoes. During the last 20 minutes of each collection hour, the collector aspirated mosquitoes from the non-illuminated bovine-baited trap. All mosquitoes were collected with oral aspirators, transferred to screened 215 $\mathrm{cm}^{3}$ (pint) cartons, killed by freezing and identified as described by Klein and Lima ${ }^{7}$. 
Klein TA, Lima JBP, Tang AT. Biting behavior of Anopheles mosquitoes in Costa Marques, Rondonia, Brazil. Revista da Sociedade Brasileira de Medicina Tropical 24: 13-20, jan-mar, 1991

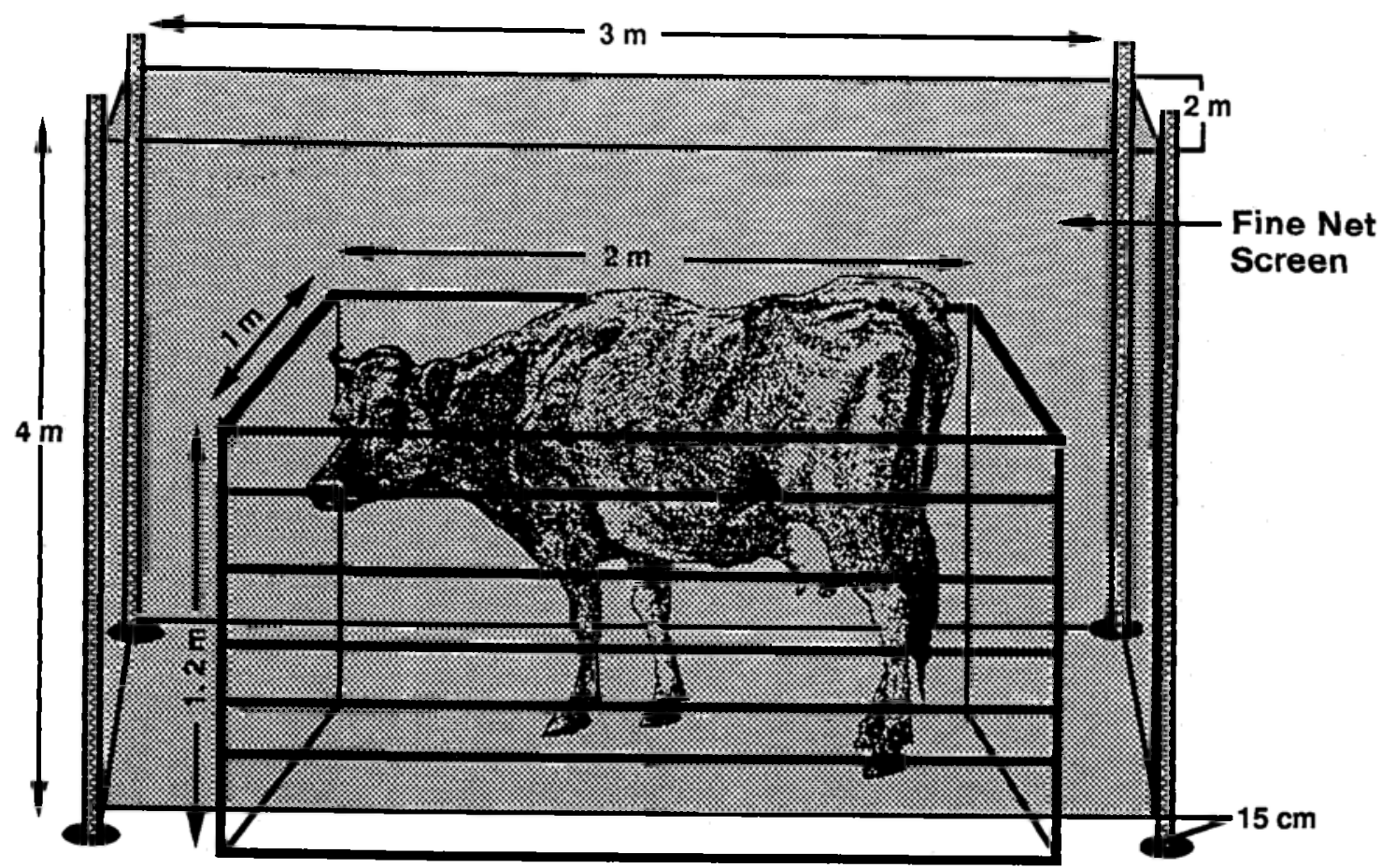

Figure 1 - Schematic drawing of the non-illuminated bovine-baited trap. Anopheline collections from the bovine-baited trap were compared to those from human-bait collections inside and outside houses.

Table 1 - Anopheles composition and preference for human-or bovine-bait from April through September, 1987, Costa Marques.

\begin{tabular}{|c|c|c|c|c|c|c|}
\hline \multirow{5}{*}{ Anopheles } & \multicolumn{6}{|c|}{ Number mosquitoes collected } \\
\hline & \multicolumn{3}{|c|}{ Urban $^{1}$} & \multicolumn{3}{|c|}{ Rural $^{l}$} \\
\hline & \multicolumn{3}{|c|}{ House 1} & \multicolumn{3}{|c|}{ House 5} \\
\hline & Bovine & Human & Human & Bovine & Human & Human \\
\hline & & (out) & (in) & & (out) & (in) \\
\hline \multicolumn{7}{|l|}{ Subgenus (Nyssorhynchus) } \\
\hline albitarsis & 6 & 0 & 2 & 933 & 150 & 71 \\
\hline braziliensis & 1 & 0 & 0 & 0 & 0 & 0 \\
\hline darlingi & 768 & 2,440 & 364 & 518 & 1,762 & 507 \\
\hline deaneorum. & 153 & 516 & 98 & 107 & 65 & 39 \\
\hline nuneztovari & 0 & 0 & 0 & 5 & 0 & 0 \\
\hline oswaldoi & 17 & 10 & 1 & 192 & 27 & 14 \\
\hline rondoni & 2 & 0 & 0 & 0 & 0 & 0 \\
\hline triannulatus & 10 & 12 & 1 & 34 & 9 & 3 \\
\hline \multicolumn{7}{|l|}{ Subgenus (Anopheles) } \\
\hline mattogrossensis & 20 & 3 & 0 & 7 & 0 & 0 \\
\hline mediopunctatus & 2 & 0 & 0 & 2 & 0 & 0 \\
\hline minor & 0 & 0 & 0 & 0 & 0 & 1 \\
\hline peryassui & 0 & 0 & 0 & 2 & 0 & 0 \\
\hline Total & 384 & 2,981 & 466 & 1,796 & 2,013 & 635 \\
\hline
\end{tabular}

${ }^{1} \mathrm{n}=15$ for number of collections. 


\section{RESULTS}

In the Costa Marques area, 12 species of adult anophelines were collected from bovine - and humanbait (Table 1). Species diversity was much greater in the rural environment than within the town of Costa Marques. Anopheles darlingi was the most frequently collected anopheline from human-bait inside and outside houses $(81 \%)$ in Costa Marques and at house $5(86 \%), 7 \mathrm{~km}$ from Costa Marques (Figures 2 and 3). Anopheles deaneorum was the second most abundant anopheline collected in the town of Costa Marques (18\%) and together with An. darlingi comprised $>99 \%$ of the total anophelines collected on humanbait at house 1. Three species, An. darlingi ( $85 \%), A n$. albitarsis (10\%) and $A n$. deaneorum (4\%) comprised $98 \%$ of the anophelines collected in human-bait at house 5. Large differences in the average number of $A n$. deaneorum and An. albitarsis were observed between house 1 and house 5 (Figure 2). Comparisons between house 1 and house 5 were only made for $A n$. darlingi and $A n$. deaneorum because other anopheline species were infrequently collected in either bovine or human-bait captures in the town of Costa Marques.

In bovine-bait collections in the town of Costa Marques, $77 \%$ of the anophelines collected were $A n$. darlingi while $15 \%$ were $A n$. deaneorum. There was only a slight increase in the percent of the remaining species of anophelines collected on bovine-bait. At house 1, there was little difference in the percentage of $A n$. darlingi and $A n$. deaneorum collected on humanand bovine-bait (Figure 2). However, $7 \mathrm{~km}$ from Costa Marques (house 5), where the diversity of anophelines was much greater, $A n$. darlingi only comprised $29 \%$ while An. albitarsis comprised $52 \%$ of the anophelines from bovine-bait collections (Figures 2 and 3 ). Anopheles darling $i$ and $A n$. deaneorum demonstrate a preference for feeding on humans and were collected in houses more frequently than the other anopheline species. Anopheles albitarsis collected on bovine-bait was $7 \mathrm{X}$ greater than those collected on human-bait (Figure 4). The percentage of $A n$. oswaldo $i$ and $A n$. triannulatus collected in bovine-baited traps was also greater for the bovine-baited trap.

\section{DISCUSSION}

Anopheles darlingi and $A n$. deaneorum are likely the most important malaria vectors in Costa Marques based on their seasonal distribution, frequency, endophilic and anthropophilic behavior and susceptibility to malaria parasites 789 . However, $A n$. deaneorum is only seasonally abundant during the late rainy to early dry season and therefore only augments malaria transmission from May through September in
Costa Marques ${ }^{7}$. Since Anopheles albitarsis is zoophilic, not susceptible to $P$. falciparum and less susceptible to oocyst infection by $P$. vivax than $A n$. darling $i^{8} 9$, we feel that this species is likely a secondary vector. Anopheles mediopunctatus is equally susceptible to sporozoite infection by $P$. falciparum but is less susceptible to oocyst infection by $P$. vivax than $A n$. darlingi and is only collected in forested areas and is also seasonal (unpublished data). This species may be seasonally important for malaria transmission for persons frequenting or living in forest habitats.

While $A n$. darlingi and $A n$. deaneorum were both more anthropophilic than other anophelines collected in Costa Marques, a large proportion were collected in the bovine-baited trap (Table 1). In areas where mosquito biting activity is crepuscular and present control measures are not effective, zooprophylaxis, or a technique to divert mosquitoes seeking a blood meal away from man, may be effective in reducing human malaria. This must be thoroughly investigated since the degree of anthropophilic behavior, location in relation to breeding sites of the animal bait and potential increase in mosquito density by increased success of blood-feeding also affects the frequency of mosquito bites on man and the infection rate of malaria ${ }^{14}$. Schultz ${ }^{12}$ demonstrated that people received approximately $40 \%$ fewer bites outdoors from An. flavirostris and An. annularis when the animal bait was placed between the human population and larval habitats or adult resting sites. However, the frequency of mosquitoes collected indoors for $A n$. flavirostris and An. annularis increased by $1.5 \mathrm{X}$ and $11.8 \mathrm{X}$, respectively, when cattle were placed near houses. White and Rosen 15 further demonstrated that there was no difference in the vectorial capacity of $A n$. gambiae and $A n$. arabiensis when cattle were not present. In the presence of cattle, the vectorial capacity of $A n$. arabiensis was much lower than An. gambiae because of its zoophilic feeding preference ${ }^{15}$. However, Sota and Mogi ${ }^{14}$ suggest that by introducing cattle, anopheline population densities may increase through greater success of blood-feeding. This may have an adverse affect by increasing the frequency of mosquito bites on man and the infection rate of malaria.

The vectorial capacity of $A n$. albitarsis as well as other species may be reduced dramatically when cattle are present due to their exophilic behavior and its preference for cattle as hosts. In the absence of alternate domestic hosts or high population densities, An. albitarsis may become an important vector of Plasmodium vivax in rural areas of Costa Marques 811 . Evidence also indicates that in the absence of alternate domestic hosts, $A n$. triannulatus and $A n$. 
Klein TA, Lima JBP, Tang AT. Biting behavior of Anopheles mosquitoes in Costa Marques, Rondonia, Brazil. Revista da Sociedade Brasileira de Medicina Tropical 24: 13-20, jan-mar, 1991

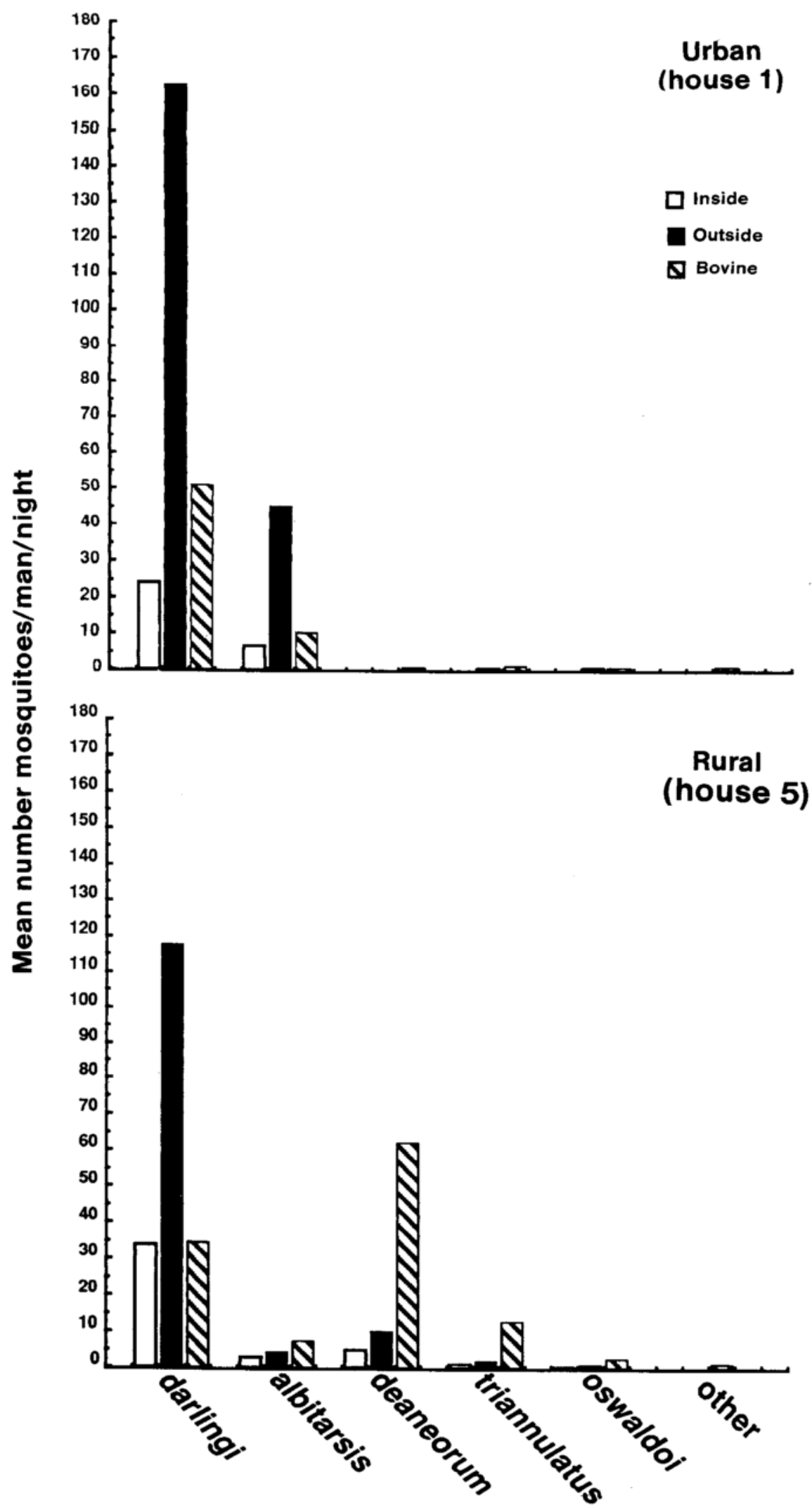


Kiein TA, Lima JBP, Tang AT. Biting behavior of Anopheles mosquitoes in Costa Marques, Rondonia, Brazil Revista da Sociedade Brasileira de Medicina Tropical 24: jan-mar, 1991

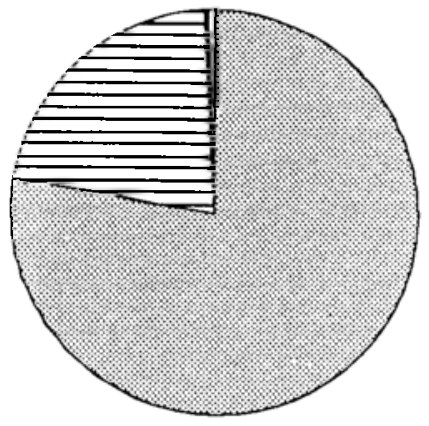

$(\mathrm{N}=466)$

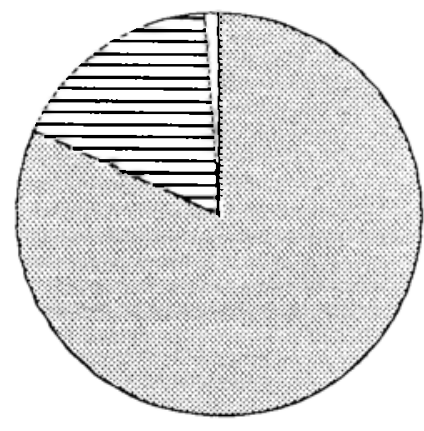

$(\mathrm{N}=2,984)$

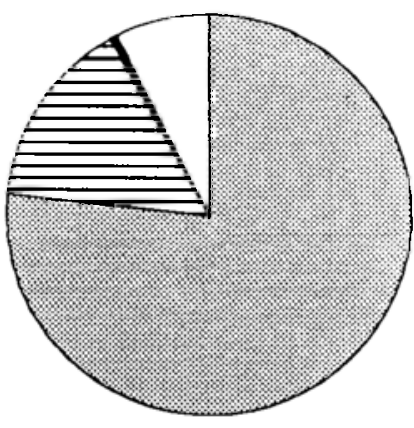

$(\mathrm{N}=1,003)$

Urban

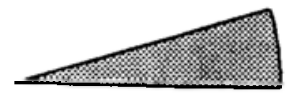

darlingi

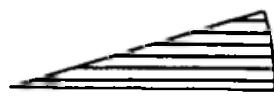

deaneorum
Human

inside

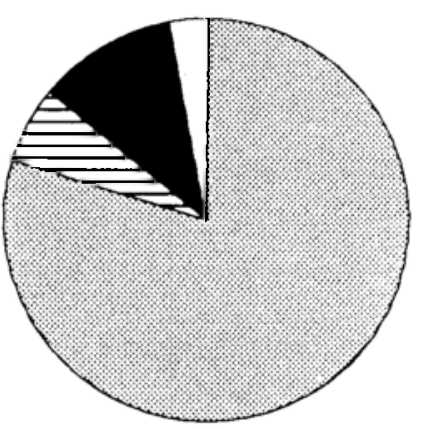

$(\mathrm{N}=635)$

Human outside

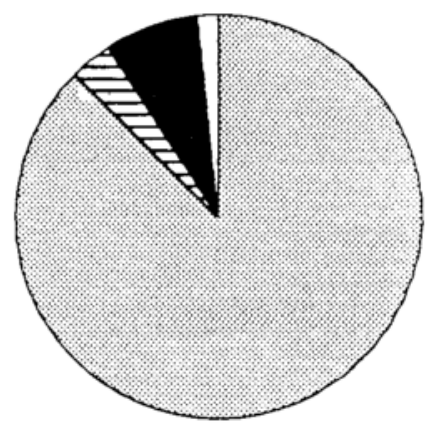

$(\mathrm{N}=2,013)$

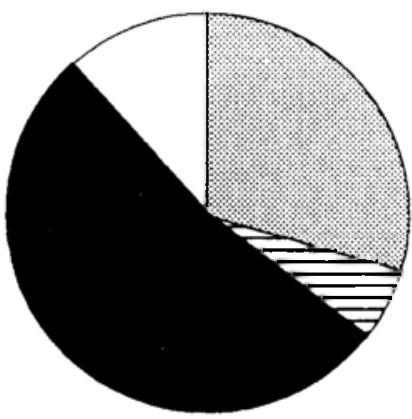

$(\mathrm{N}=\mathbf{1 , 8 0 0 )}$

Rural

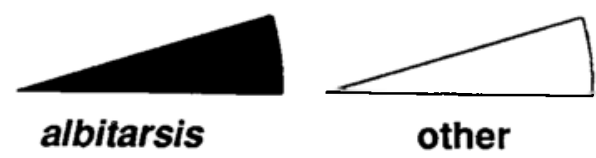

Figure 3 - Percentage of Anopheles mosquitoes collected indoors and outdoors on human-bait outdoors and on bovinebait in the town of Costa Marques (urban) andat $\mathrm{km} 7$ (rural), BR 429, Costa Marques, Rondonia from April through September, 1987. 
Klein TA, Lima JBP, Tang AT. Biting behavior of Anopheles mosquitoes in Costa Marques, Rondonia, Brazil. Revista da Sociedade Brasileira de Medicina Tropical 24: 13-20, jan-mar, 1991
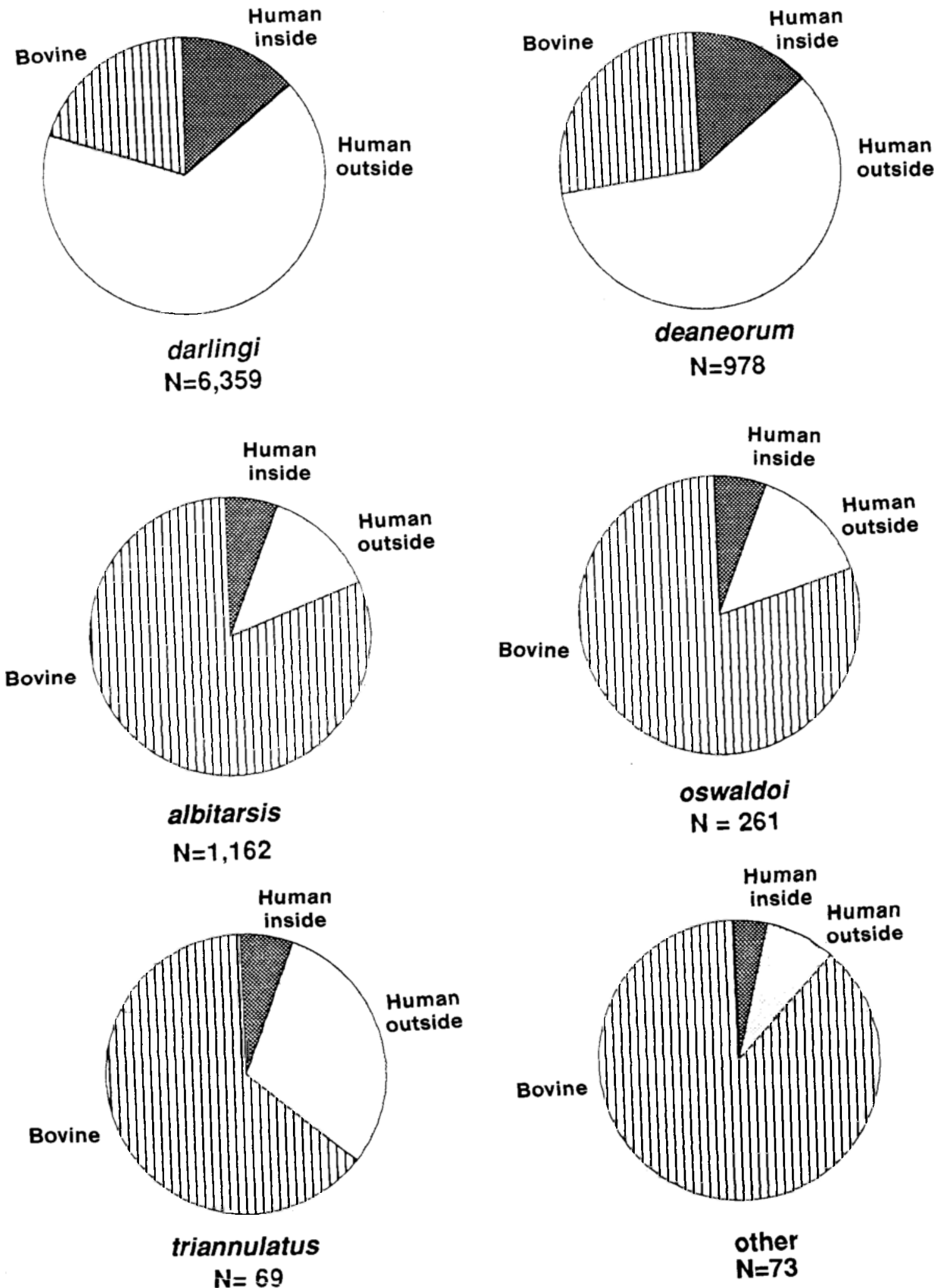

triannulatus

$$
\mathbf{N}=69
$$

Figure 4 - Comparison of feeding preference of Anopheles species collected on human-bait inside and outside houses I and 5 on bovine-bait, Costa Marques, Rondonia, from April through September, 1987. 
oswaldoi readily bite man. However, their importance in malaria transmission is probably much less because sporozoites were rarely found in the salivary glands of dissected mosquitoes in malaria susceptibility tests 89 .

It is difficult to make generalizations from one location to another because of current taxonomic problems with anophelines in the Amazon region 27. Data in the literature are often contradictory. For example, Faran and Linthicum ${ }^{4}$ and Charlwood and Wilkes ${ }^{1}$ report that An. triannulatus is zoophilic, rarely enters houses, but readily feeds on man outdoors, while Gabaldon ${ }^{5}$ reports that this specie primarily bites indoors. In our study, An. triannulatus rarely entered houses, but was frequently collected in humanbait collections in forested areas and along river margins. A larger percentage of An. triannulatus was collected in a bovine-baited trap, indicating a zoophilic preference.

Faran and Linthicum ${ }^{4}$ report that $A n$. oswaldo $i$ adults are largely restricted to the forest, and are exophilic and zoophilic. In other studies, populations of An. oswaldoi were generally restricted to forest habitats and these mosquitoes readily bite man during the early evening and daytime when the sky was overcast (Klein and Lima, unpublished data).

Shannon and Davis 13 indicated that $A n$. albitarsis sensu lato did not, as a rule, enter houses as frequently as $A n$. darlingi, but it will invade houses in relatively large numbers. In Costa Marques, $A n$. deaneorum readily enters houses, is anthropophilic, and is a vector of both $P$. falciparum and $P$. vivax. In contrast, An. albitarsis in Costa Marques is zoophilic, but will also bite man and enter poorly constructed houses with large spaces in the walls ${ }^{6}$.

In summary, zooprophylaxis may reduce the vectorial capacity of anopheline human malaria vectors in some areas of Brazil. However, the endophilic/ exophilic and anthropophilic/zoophilic behavior of potential vector populations need to be evaluated more closely to determine the effectiveness of this method against malaria. With a strongly anthropophilic species like $A n$. darlingi, alternate host availability may have little effect in reducing the incidence of malaria. Additionally, behavioral studies frequently lead to recognition of taxonomic problems and identification of potential vector populations/species. Resolving vector systematic problems ultimately results in a more effective malaria control program by allowing specific vector species to be identified and targeted.

\section{RESUMO}

Para determinar o comportamento antropofilico $e$ zoofilico dos anofelinos, foram capturados mosquitos na periferia e na zona urbana de Costa Marques, Rondônia,
Brasil. Foram comparadas as capturas feitas à noite, com iscas bovinas e humanas, dentro e fora de casa. $O$ Anopheles darlingi $e o$ Anopheles deaneorum foram mais antropofilicos do que os outros anofelinos capturados. $O$ restante das espécies anofelinas foi capturado mais freqüentemente nas iscas bovinas do que nas humanas. Anopheles darlingi $e$ Anopheles deaneorum foram capturados dentro de casa com mais freqüência do que as outras espécies anofelinas. Porém, quando a captura foi feita em casas com muitas aberturas nas paredes houve pouca diferenca nas porcentagens de cada espécie sugadora de humanos dentro e fora de casa. Anopheles darlingi foi o mosquito capturado com mais freqüencia, dentro e fora de casa, e apresentava maior antropofilia em relação aos outros anofelinos presentes.

Palavras-chaves: Anopheles sp. Brasil. Comportamento. Antropofilico. Zoofilico.

\section{ACKNOWLEDGMENTS}

We gratefully appreciate Luis Gil, Jose Rodrigues and Maria Fatima Barros for their technical support. We thank the following colleagues Stephen Hembree, USAMRU-Brazil, Aluizio R. Prata, Vanize Macedo and Mauro S. Tada, University of Brasilia, Brasilia, and Lyman Roberts, Walter Reed Army Institute of Research for their support.

\section{REFERENCES}

1. Charlwood JD, Wilkes TJ. Observations on the biting activity of Anopheles triannulatus bachmanni from the Mato Grosso, Brazil. Acta Amazonica 11:67-69, 1981.

2. Deane LM. Malaria studies and control in Brazil. The American Journal of Tropical Medicine and Hygiene 38: 223-230, 1988.

3. Deane LM, Causey OR, Deane MP. Notas sobre a distribuiçāo e a biologia dos anophelinos das regiões Nordestina e Amazônica do Brasil. Revista do Serviço Especial de Saúde Pública 1: 827-965, 1948.

4. Faran ME, Linthicum KJ. A handbook of the Amazon species of Anopheles (Nyssorhynchus) (Diptera: Culicidae). Mosquitoes Systems 13: 1-81, 1981.

5. Gabaldon A. Malaria incidence in the West Indies and South America. In: Boyd, Mark F (ed) Malariology. WB. Saunders Co., Philadelphy p. 764-787, 1949.

6. Greenwood BM. The microepidemiology of malaria and its importance to malaria control. Transaction of the Royal Society of Tropical Medicine and Hygiene 83 (suppl.): 25-29, 1989.

7. Klein TA, Lima JBP. Seasonal distribution and biting patterns of Anopheles mosquitoes in Costa Marques, Rondonia, Brazil. Journal of the American Mosquito Control Association 6: 700-707, 1990.

8. Kelin TA, Lima JBP, Tada MS. Comparative susceptibility of anopheline mosquitoes to Plasmodium falciparum in Rondonia, Brazil. The American Journal of Tropical Medicine and Hygiene 44: 598-603, 1991. 
Klein TA, Lima JBP, Tang AT. Biting behavior of Anopheles mosquitoes in Costa Marques, Rondonia, Brazil. Revista da Sociedade Brasileira de Medicina Tropical 24: 13-20, jan-mar, 1991

9. Klein TA, Tada MS, Lima JBP. Comparative susceptibility of potential anopheline vectors to Plasmodium falciparum in Rondonia, Brazil. The American Journal of Tropical Medicine and Hygiene, 1991.

10. Marques AC. Human migration and the spread of malaria in Brazil. Parasitology Today 3: 166-170, 1987.

11. Molyneaux L, Gramiccia G. The Garki Project: Research on the epidemiology and control of malaria in Sudan savannah of West Africa. World Health Organization p. $311,1980$.

12. Schultz GW. Animal influence on man-biting rates at a malarious site in Palawan, Philippines. Southeast Asian Journal of Tropical Medicine and Public Health 20: 49$53,1989$.
13. Shannon RC, Davis NC. Observations on the Anophelini (Culicidade) of Bahia, Brazil. Annals of the American Entomology Society 23: 467-505, 1930.

14. Sota T, Mogi M. Effectiveness of zooprophylaxis in malaria control: a theoretical inquiry, with a model for mosquito populations with two bloodmeal hosts. Veterinary and Entomology Medicine 3: 337-345, 1989.

15. White GB, Rosen P. Comparative studies on sibling species of the Anopheles gambiae complex (Diptera Culicidae). II. Ecology of species A and B in Savanna aound Kaduna, Nigeria during transition from wet to dry season. Bulletin of Entomology Research 62:613. 1973. 